\title{
ANALYSIS OF BRAND CHARACTERISTICS OF MUSIC ARTISTS IN THE POP CD MARKET: CASE OF JAPAN
}

\author{
Ushio Sumita
}

\author{
Kazuki Takahashi \\ University of Tsukuba
}

\author{
Jun Yoshii
}

(Received November 19, 2009; Revised January 28, 2011)

\begin{abstract}
Following [23], the customers for the CD market are classified into twelve segments along two axes: "Artist Loyalty" and "Market Sensitivity". The purchasing behavior of individual customers is formulated as a Markov chain in discrete time. The transition structure of the customers across the twelve segments is common. However, the market segmentation is reflected by altering transition probabilities in terms of eight different parameters. In [23], repeated vector-matrix multiplications are employed for evaluating necessary probabilistic entities. In this paper, through the spectral analysis of the transition probability matrix, the state probability vector of the underlying Markov chain is obtained in a closed form, which enables one to apply a nonlinear optimization solver for estimating the eight parameters involved so as to minimize the Euclidian distance between the expected number of CDs sold over 20 weeks calculated from the Markov model and the actual POS data. Furthermore, several new indicators are evaluated for capturing the brand characteristics of individual music artists. Five leading Japanese music artists are actually analyzed, suggesting new effective marketing strategies for each of them. The proposed approach can be applied to any market in which products are likely to be purchased only once.
\end{abstract}

Keywords: Applied probability, CD market, customer segmentation, Markov chain, spectral analysis, brand characteristics

\section{Introduction}

Application of Markov chains to marketing analysis dates back to 1950s originated by the work of Anderson and Goodman [1]. For the next decade, many researchers developed various Markov models represented by the brand switching models of Harary and Lipstein [7], Ehrenberg [5], Hartung and Fisher [8] and Massy and Morrison [13]. However, such Markov models could not explain real data too well because of the assumption that all customers share a common transition probability matrix. For analyzing customer behavior in marketing, the diffusion models then emerged, see e.g. Bass [2], Horsky and Simon [10] and Horsky [9]. The unique feature of the diffusion process approach could be found in that the whole market would be expressed as the aggregated outcome of individual behaviors of infinitely many customers. While microscopic analysis of individual customer behaviors would be lost, rather simple diffusion equations would enable one to conduct a variety of analyses concerning the customer behavior as a whole.

In 1990s, as the market economy matured, many researchers in marketing began to pay attention to market segmentation, see e.g. Moorthy and Png [15], Raaij and Verhallen [20], Jedidi, Jagpal, and Desarbo [11], Moschis, Lee, and Mathur [16], Kucukemiroglu [12], Peter and Olson [18], and Wedel and Kamakura [24], among others. In this context, Markov models revived to some extent, where the pitfall of being unable to fit real data was resolved by applying different transition probability matrices to different market segments. A Markov model by Poulsen [19], for example, successfully analyzed brand switching phenom- 
ena with excellent data fit by mixing transition probability matrices across different market segments. Other examples of Markov models in marketing can be found in Danaher [4], Ching, Fung and Ng [3], Ha, Bae and Park [6], Rust, Lemon and Zeithaml [21] and Sumita, Ise and Yonezawa [22], which analyzed the whole market from the strategic point of view of corporations involved concerning the market entry and retreat. Markov models have been also applied to capture the customer behavior not only after purchasing but also before purchasing, see e.g. Montgomery, Li, Srinivasan and Liechty [14] and Netzer, Latten and Srinivasan [17]. This paper follows this line of research by developing a Markov chain model for understanding the brand characteristics of individual music artists in the CD market.

A typical CD has an anomalous product life cycle in that as soon as the CD is released, its sales would increase sharply and then converge to 0 in about twenty weeks. This peculiarity concerning the product life cycle of CDs makes it difficult to develop a Markov model that can fit real data. The purpose of this paper is to overcome this difficulty by introducing a new approach for customer segmentation in the CD market, enabling one to obtain the excellent fitness for real data and to comprehend the brand characteristics of music artists in the CD market. While the study relies upon the specific data of the Japanese CD market, the proposed approach could be applied to any market in which products are likely to be purchased only once, provided that the data set necessary for estimating the underlying parameter values could be obtained.

Following Sumita et al. [23], the customer segmentation for the CD market is considered, where the customers are classified into twelve segments along two axes: "Artist Loyalty" consisting of three different levels (Addict, Fan, and Neutral), and "Market Sensitivity" with four different levels (Ultra Sensitive, Sensitive, Normal, and Insensitive). The artist loyalty of a customer to a music artist is measured by the number of CDs of the artist purchased by the customer, while the market sensitivity of the customer to the J-POP CD market is defined by ranking how soon a J-POP CD is purchased by the customer since the release of the CD.

As in [23], given a music artist, his/her CD and the segment to which a customer belongs, the purchasing behavior of that customer for that CD is formulated as a Markov chain in discrete time defined on the following five states: Unknown, Known, Interested, Purchased, and Not Purchased. Since a music CD is not likely to be purchased repeatedly, the two states, Purchased and Not Purchased, are absorbing. The transition structure of the customers across the twelve segments is common. However, the market segmentation is reflected by altering transition probabilities in terms of eight different parameters. The entire market for the artist is then expressed as an independent sum of all such customers. Through the spectral analysis of the transition probability matrix, the state probability vector of the underlying Markov chain is obtained in a closed form, which enables one to apply an optimization solver for estimating the eight parameters involved so as to minimize the Euclidian distance between the expected number of CDs sold over 20 weeks calculated from the Markov model and the actual POS data. Furthermore, using the resulting eight parameter values, several new indicators are obtained for capturing the brand characteristics of individual music artists. The whole procedure is applied to analyze the brand characteristics of five leading Japanese music artists, suggesting new effective marketing strategies for each of them. This paper is a sequel to the preliminary paper [23] written in Japanese, and is further advanced in the following ways.

(1) In the previous paper, the expected values of interest associated with the Markov model were computed through vector-matrix multiplications, so that the optimal parameter 
values could be estimated only through repeated computations of such expected values on a grid in the parameter space. Consequently, the number of parameters tolerated in the optimization was limited to six. In this paper, the spectral representation of the transition probability matrix of the Markov model is obtained explicitly. Accordingly, the expected values of interest are expressed in a closed form. A nonlinear optimization solver can then be applied for solving the optimization problem, enabling one to estimate the entire eight parameters.

(2) The strength of a music artist in the CD market may be highlighted in terms of three factors: the total sales, the speed of the start-up sales and the volume of the longterm sales in the tail. In the previous paper [23], these three factors are discussed only qualitatively based on the expected sales as a function of time calculated from the estimated optimal parameter values and repeated vector-matrix multiplications. In this paper, the number of sales by week $\tau$ and the number of sales after week $\tau$, denoted by $S_{H}(\tau)$ and $S_{T}(\tau)$ respectively, are formally introduced, where week $\tau$ accounts for the number of weeks since the release of the CD. Consequently, the three factors can be captured in terms of quantifiable measures by deriving the probability distributions of $S_{H}(\tau)$ and $S_{T}(\tau)$ explicitly.

(3) In this paper, thanks to the suggestions of two anonymous referees, the pre-release consumer behavior is incorporated by starting a Markov model at time -2. Furthermore, the definitions concerning Artist Loyalty are modified so as to reflect the reality better. Also, the actual release days of the CDs for the study are extracted from Amazon.com, while they were approximated, in [23], by the first purchase day obtained from the POS data.

The structure of this paper is as follows. The data set used in this study is first described in Section 2. A new approach for customer segmentation in the CD market is proposed in Section 3, where the customers are classified into twelve segments along two axes: "Artist Loyalty" and "Market Sensitivity". A Markov chain model in discrete time is developed in Section 4 to describe the purchasing behavior of individual customers in each market segment. The transition structure of the customers across the twelve segments is common. However, the market segmentation is reflected by altering transition probabilities in terms of eight different parameters. Section 5 is devoted to development of algorithmic procedures for estimating the eight parameter values based on the spectral analysis of the underlying transition probability matrix. The resulting parameter values are then utilized in Section 6 for analyzing the brand characteristics of the five leading Japanese music artists under the study. Based on this analysis, new effective marketing strategies are also suggested. Finally, some concluding remarks are given in Section 7 .

In this paper, matrices and vectors are indicated by double-underlines $(\underline{a}, \underline{b}$, etc.) and single-underlines $(\underline{x}, \underline{y}$, etc.) respectively. The identity matrix is denoted by $\underline{\underline{I}}$ and the zero matrix by $\underline{\underline{0}}$. The vector with all components equal to 1 is written as $\underline{1}$.

\section{Data Description}

The set of POS data used in this study is provided, for the Data Analysis Competition 2005 , by a company having ten retail stores for CD sales in Japan. The data set consists of purchasing records of the customers who are house-card members of the company, covering the period of 24 months between September 2003 and August 2005. From the original data set, a subset is constructed for the study by extracting the purchasing records of the customers who purchased at least one of POP CDs by Japanese artists during the data 
period. The top 5 Japanese music artists are then selected based on the total sales monetary amount in the data period for understanding their brand characteristics. Also chosen are their CDs which were released within the data period with more than 20 weeks remained before the end of the period. The selected artists and their respective CDs are listed in Table 1. Mr.Children, Ketsumeishi and EXILE are music groups. For simplicity, however, each of them is referred to as an artist in this paper.

Table 1: Selected artists and their respective CDs

\begin{tabular}{|c|c|}
\hline Artist Name & (S: single A: album) \\
\hline Mr.Children & Palm(掌/くるみ)(S), Sign(S), Sound of Beatitude(シフクノオト)(A) \\
\hline \multirow[t]{2}{*}{ Ketsumeishi } & Ketsuno Plice 3(ケツノポリス 3)(A), Tear(涙)(S), \\
\hline & Bump into You(君に BUMP)(S), Cherry-Blossom(さくら)(S) \\
\hline Ayumi Hamasaki & Memorial Address(A), INSPIRE(S), MY STORY(A), STEP You(S) \\
\hline \multirow[t]{3}{*}{ Ken Hirai } & Ken's Bar(A), Close Your Eyes(瞳をとじて)(S), \\
\hline & You Are My Friend(キミはともだち)(S), SENTIMENTALovers(A), \\
\hline & Before Affection Deepens(思いがかさなるその前に…)(S) \\
\hline EXILE & EXILE ENTERTAINMENT(A), PERFECT BEST(A), \\
\hline & SINGLE BEST(A) \\
\hline
\end{tabular}

\section{Customer Segmentation Matrix}

Fans of a music artist often consist of multiple groups with different level of loyalty. Loyal fans may follow the activity of the music artist closely. However, they may not necessarily pay attention to the entire POP CD market all the time. Some POP music fans may not be crazy about any specific music artist. However, they may always watch the entire POP $\mathrm{CD}$ market closely and purchase a $C D$ whenever they like it. In order to reflect layers of such different POP music fans, the Japanese POP CD market is decomposed, as in [23], into twelve segments along two axes: "Artist Loyalty" and "Market Sensitivity".

With respect to "Artist Loyalty", customers are classified into 3 segments: Addict, Fan and Neutral. We define $\mathcal{I} \stackrel{\text { def }}{=}\{A d d, F a n, N e u\}$. A customer is defined to be an Addict of a music artist if he/she has purchased three or more CDs of the artist. A customer is a Fan of a music artist if he/she has purchased two CDs of the artist. Finally, a customer is a Neutral of a music artist if he/she has purchased at most one CD of the artist. Here, the artist loyalty of a customer for a music artist is determined by considering all CDs of the artist which are sold in the market during the data period and are not limited to the selected CDs of the artist for the study. More specifically, the numbers of CDs used for this purpose are 40 for Mr.Children, 21 for Ketsumeishi, 26 for Ken Hirai, 70 for Ayumi Hamasaki and 28 for EXILE.

Another axis for the market segmentation is "Market Sensitivity" consisting of four categories: Ultra Sensitive, Sensitive, Normal and Insensitive. We define $\mathcal{J} \stackrel{\text { def }}{=}\{$ Usen, Sen, Norm, Ins $\}$. A customer is defined to be Ultra Sensitive if he/she has purchased a CD within 3 days since the release of the CD. He/She is Sensitive (Normal) if a CD is purchased between 4 to 14 days (15 and 28 days) since the release of the CD. Finally, a customer is Insensitive if he/she has not purchased any CD of a music artist or the purchase is done after 29 days or more since the release of the CD. These definitions of $|\mathcal{I}| \times|\mathcal{J}|=12$ segments are summarized in Table 2.

For each selected artist, the relative sizes of the twelve segments can be estimated from the POS data based on the definitions in Table 2. The resulting table is called the customer 
Table 2: "Artist Loyalty" and "Market Sensitivity"

\begin{tabular}{|c|c|}
\hline Artist Loyalty & Definition \\
\hline Addict & a customer who purchased 3 or more CDs of an artist \\
\hline Fan & a customer who purchased 2 CDs of an artist \\
\hline Neutral & a customer who has purchased at most one CD of an artist \\
\hline Market Sensitivity & Definition \\
\hline Ultra Sensitive & a customer who purchased a CD within 3 days since the release of the CD \\
\hline Sensitive & $\begin{array}{l}\text { a customer who purchased a CD between } 4 \text { and } 14 \text { days since the release } \\
\text { of the CD }\end{array}$ \\
\hline Normal & $\begin{array}{l}\text { a customer who purchased a CD between } 15 \text { and } 28 \text { days since the release } \\
\text { of the CD }\end{array}$ \\
\hline Insensitive & $\begin{array}{l}\text { a customer who has not purchased any CD of a music artist or purchased } \\
\text { a CD since more than } 28 \text { days later since the release of the CD }\end{array}$ \\
\hline
\end{tabular}

segmentation matrix. More specifically, let $N_{I J}(a)$ be the number of customers of artist $a$ in segment $(I, J) \in \mathcal{I} \times \mathcal{J}$. The customer segmentation matrix for artist $a$, denoted by $\underline{\underline{Q}}(a)$, is then defined by

$$
\underline{\underline{Q}}(a) \stackrel{\text { def }}{=}\left[Q_{I J}(a)\right] ; Q_{I J}(a) \stackrel{\text { def }}{=} \frac{N_{I J}(a)}{N_{P O S}}
$$

where $N_{P O S}$ is the number of customers who have purchased at least one Japanese POP CD during the data period. For the data employed, one has $N_{P O S}=230,933$. The customer segmentation matrices of the top five artists selected in Section 2 are shown in Table 3.

\section{Development of a Markov Chain Model for Describing Customer Behaviors in the POP CD Market}

In this section, a stochastic model is developed for describing the purchasing behavior of individual customers for a $\mathrm{CD}$ of a music artist. More specifically, let $\{J(k): k=0,1,2, \ldots\}$ be a Markov chain in discrete time defined on the following five states: (1) Unknown, (2) Known, (3) Interested, (4) Purchased, and (5) Not Purchased. The transition structure of the Markov chain is depicted in Figure 1, where the time unit is taken to be a week.

A customer in segment $(I, J) \in \mathcal{I} \times \mathcal{J}$ may not know about the release of the CD under consideration at time $\tau$, which means that the customer is in state (1) at time $\tau$. With probability $\alpha_{1: I J}$, the CD remains to be unknown to the customer, and the customer comes to know the CD with probability $\beta_{1: I J}=1-\alpha_{1: I J}$, moving to state (2). The self-transition probabilities $\alpha_{i: I J}(i=2,3)$ represent a degree of hesitation of the customer for advancing his/her interest toward the decision of purchasing or not purchasing. The probabilities $\beta_{i: I J}$ $(i=2,3)$ describe a degree of inclination of the customer toward purchasing, corresponding to the state move from (2) to (3) and that from (3) to (4) respectively. The customer decides not to buy the CD with probabilities $\gamma_{i: I J}(i=2,3)$ with state transition from (2) to (5) and that from (3) to (5) respectively. Since a music CD is not likely to be purchased repeatedly, the two states, (4) Purchased and (5) Not Purchased, are absorbing.

The transition structure of the customers across the twelve segments is assumed to be common. However, the market segmentation is reflected by altering transition probabilities in terms of eight different parameters and the initial state in the following manner. For those customers who belong to the customer segment $(I, J) \in \mathcal{I} \times \mathcal{J}$, we first define $\beta_{1: I J}=p_{I: J}$, which represents a chance for a customer to come to know the CD under consideration during 
Table 3: Customer segmentation matrices of the five artists $\left(N_{P O S}=230,933\right)$

\begin{tabular}{|c|c|c|c|c|c|}
\hline Mr.Children & $\begin{array}{l}N(M r . C \\
N_{P O S}\end{array}$ & $\begin{array}{l}\text { iildren }) \\
\mathrm{V}(M r . C\end{array}$ & $\begin{array}{l}16,885 \\
\text { ldren) }=\end{array}$ & 14,048 & \\
\hline$I \backslash J$ & Usen & Sen & Norm & Ins & sum \\
\hline Add & 0.00524 & 0.00018 & 0.00003 & 0.00012 & 0.00558 \\
\hline Fan & 0.00828 & 0.00083 & 0.00020 & 0.00048 & 0.00979 \\
\hline $\mathrm{Neu}$ & 0.49516 & 0.20187 & 0.08613 & 0.20147 & 0.98463 \\
\hline sum & 0.50868 & 0.20288 & 0.08637 & 0.20207 & 1.00000 \\
\hline Ketsumeishi & \multicolumn{5}{|c|}{$\begin{array}{l}N(\text { Ketsumeishi })=13,408 \\
N_{P O S}-N(\text { Ketsumeishi })=217,525\end{array}$} \\
\hline$I \backslash J$ & Usen & Sen & Norm & Ins & sum \\
\hline Add & 0.00237 & 0.00020 & 0.00007 & 0.00014 & 0.00279 \\
\hline Fan & 0.00476 & 0.00070 & 0.00022 & 0.00047 & 0.00615 \\
\hline $\mathrm{Neu}$ & 0.50155 & 0.20198 & 0.08608 & 0.20145 & 0.99106 \\
\hline sum & 0.50868 & 0.20288 & 0.08637 & 0.20207 & 1.00000 \\
\hline Ken Hirai & \multicolumn{5}{|c|}{$\begin{array}{l}N(\text { Ken Hirai })=11,816 \\
N_{P O S}-N(\text { Ken Hirai })=219,117\end{array}$} \\
\hline$I \backslash J$ & Usen & Sen & Norm & Ins & sum \\
\hline$A d d$ & 0.00140 & 0.00010 & 0.00002 & 0.00005 & 0.00158 \\
\hline Fan & 0.00383 & 0.00071 & 0.00021 & 0.00029 & 0.00504 \\
\hline $\mathrm{Neu}$ & 0.50345 & 0.20207 & 0.08613 & 0.20173 & 0.99338 \\
\hline sum & 0.50868 & 0.20288 & 0.08637 & 0.20207 & 1.00000 \\
\hline $\begin{array}{c}\text { Ayumi } \\
\text { Hamasaki }\end{array}$ & \multicolumn{5}{|c|}{$\begin{array}{l}N(\text { Ayumi Hamasaki })=8,828 \\
N_{P O S}-N(\text { Ayumi Hamasaki })=222,105\end{array}$} \\
\hline$I \backslash J$ & Usen & Sen & Norm & Ins & sum \\
\hline$\overline{A d d}$ & 0.00396 & $\overline{0.00016}$ & 0.00003 & 0.00004 & 0.00418 \\
\hline Fan & 0.00459 & 0.00053 & 0.00010 & 0.00009 & 0.00532 \\
\hline $\mathrm{Neu}$ & 0.50013 & 0.20220 & 0.08624 & 0.20194 & 0.99050 \\
\hline sum & 0.50868 & 0.20288 & 0.08637 & 0.20207 & 1.00000 \\
\hline $\begin{array}{c}\text { EXILE } \\
\text { Mr.Children }\end{array}$ & \multicolumn{5}{|c|}{$\begin{array}{l}N(E X I L E)=8,338 \\
N_{P O S}-N(E X I L E)=222,595\end{array}$} \\
\hline$I \backslash J$ & Usen & Sen & Norm & Ins & sum \\
\hline Add & 0.00177 & 0.00005 & 0.00001 & 0.00001 & 0.00184 \\
\hline Fan & 0.00294 & 0.00022 & 0.00007 & 0.00008 & 0.00330 \\
\hline $\mathrm{Neu}$ & 0.50398 & 0.20262 & 0.08628 & 0.20198 & 0.99486 \\
\hline sum & 0.50868 & 0.20288 & 0.08637 & 0.20207 & 1.00000 \\
\hline
\end{tabular}

Note. $N(a)$ denotes the number of customers who purchased at least one CD of artist $a$ on the POS data

a week. It is assumed that this probability is equal to the probability of encountering an opportunity to deepen the interest of the customer so that $\beta_{2: I J}=\beta_{1: I J}$. However, for making the final decision of purchasing, it may demand more careful consideration and we reduce $\beta_{3: I J}$ by $\beta_{3: I J}=\beta_{2: I J} \cdot \zeta$ with $0<\zeta<1$. For state (1), one has $\alpha_{1: I J}=1-\beta_{1: I J}$. For states (2) and (3), the remaining probabilities $1-\beta_{i: I J}$ for $i=2,3$ are split between hesitation with probability $r_{I}$ and making the decision of not purchasing it with probability $1-r_{I}$. We assume that $p_{I: J}=p_{I}$ for $I \in \mathcal{I}=\{$ Add,Fan, Neu $\}$ and $J \in \mathcal{J} \backslash\{U$ sen $\}$. For $J=U$ sen, this probability reflecting the inclination toward purchasing is increased as $p_{I: U s e n}=p_{I}+\xi$ where $0<\xi<1-p_{I}$.

Concerning the initial state of a customer, the customer may be acquainted with a CD under consideration even before it is released in the market. However, it would be impossible to actually purchase it prior to the release. In order to incorporate this aspect of the purchasing behavior, following the suggestion of an anonymous referee, we assume that 


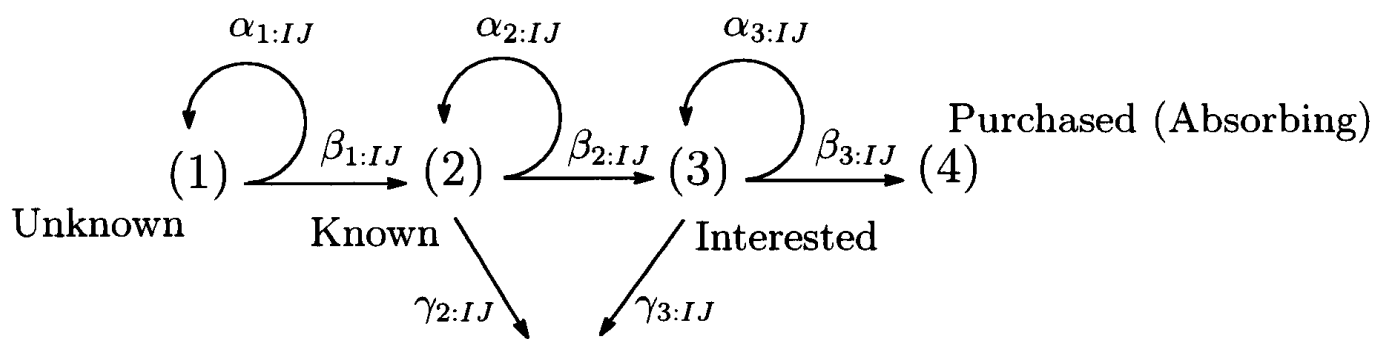

(5)

Not Purchased (Absorbing)

Figure 1: State transition diagram

all customers in $(I, J)$ behave for two weeks prior to the release of a CD according to the stochastic matrix associated with $(I, J)$ except that $\beta_{3: I J}$ is set to be 0 , and the initial state depending on $J$ as described below. At time -2 , those customers in $(I$, Ins) for $I \in \mathcal{I}$ are assumed to start in state (1). The initial state of those customers in $(I, N o r m)$ for $I \in \mathcal{I}$ at time -2 are set to be state (2), and those in $(I, U s e n)$ or $(I, S e n)$ for $I \in \mathcal{I}$ are assumed to start at state (3). Consequently, at time 0 , the state of a customer in $(I, J)$ is expressed in terms of the state probability vector of the Markov chain above with $\beta_{3: I J}=0$ from time -2 to time 0 .

In summary, through the eight parameters $p_{A d d}, p_{F a n}, p_{N e u}, r_{A d d}, r_{F a n}, r_{N e u}, \zeta$ and $\xi$ together with the way the state probability vector at time 0 is set, the stochastic behavior of those customers in $(I, J) \in \mathcal{I} \times \mathcal{J}$ can be characterized differently, as shown in Tables 4 and 5.

Table 4: $\alpha_{i: I J}, \beta_{i: I J}$ and $\gamma_{i: I J}$

\begin{tabular}{lcccccc}
\hline & $\alpha_{1: I J}$ & $\alpha_{2: I J}$ & $\alpha_{3: I J}$ & $\beta_{1: I J}$ & $\beta_{2: I J}$ & $\beta_{3: I J}$ \\
\hline \hline Addict & $1-p_{\text {Add:J }}$ & $r_{\text {Add }}\left(1-p_{\text {Add:J }}\right)$ & $r_{\text {Add }}\left(1-p_{\text {Add:J }} \cdot \zeta\right)$ & $p_{\text {Add:J }}$ & $p_{\text {Add:J }}$ & $p_{\text {Add:J }} \cdot \zeta$ \\
Fan & $1-p_{\text {Fan:J }}$ & $r_{\text {Fan }}\left(1-p_{\text {Fan:J }}\right)$ & $r_{\text {Fan }}\left(1-p_{\text {Fan:J }} \cdot \zeta\right)$ & $p_{\text {Fan:J }}$ & $p_{\text {Fan:J }}$ & $p_{\text {Fan:J }} \cdot \zeta$ \\
Neutral & $1-p_{\text {Neu:J }}$ & $r_{\text {Neu }}\left(1-p_{\text {Neu:J }}\right)$ & $r_{\text {Neu }}\left(1-p_{\text {Neu:J }} \cdot \zeta\right)$ & $p_{\text {Neu:J }}$ & $p_{\text {Neu:J }}$ & $p_{\text {Neu:J }} \cdot \zeta$ \\
\hline
\end{tabular}

\begin{tabular}{lcc}
\hline & $\gamma_{2: I J}$ & $\gamma_{3: I J}$ \\
\hline \hline Addict & $\left(1-r_{\text {Add }}\right)\left(1-p_{\text {Add:J }}\right)$ & $\left(1-r_{\text {Add }}\right)\left(1-p_{\text {Add:J }} \cdot \zeta\right)$ \\
Fan & $\left(1-r_{\text {Fan }}\right)\left(1-p_{\text {Fan:J }}\right)$ & $\left(1-r_{F a n}\right)\left(1-p_{\text {Fan:J }} \cdot \zeta\right)$ \\
Neutral & $\left(1-r_{\text {Neu }}\right)\left(1-p_{\text {Neu:J }}\right)$ & $\left(1-r_{\text {Neu }}\right)\left(1-p_{\text {Neu:J }} \cdot \zeta\right)$ \\
\hline
\end{tabular}

Note 1. $p_{I: J}=p_{I}$ for $J \in \mathcal{J} \backslash\{U$ sen $\}$ and $p_{I: U s e n}=p_{I}+\xi$

Note 2. $p_{\text {Neu:J }} \leqslant p_{F a n: J} \leqslant p_{A d d: J}$ and $r_{N e u} \leqslant r_{F a n} \leqslant r_{A d d}$

Table 5: The initial state of the customer at time -2 for $J \in \mathcal{J}$

\begin{tabular}{ccccc}
\hline$J$ & Usen & Sen & Nor & Ins \\
\hline Initial State & 3 (Interested) & 3 (Interested) & 2 (Known) & 1 (Unknown) \\
\hline
\end{tabular}

Given a music artist, his/her CD and the segment to which a customer belongs, the Markov chain model described above enables one to capture the state of the customer at the beginning of week $\tau$. The entire market for the artist is then expressed as an independent sum of the Markov chains corresponding to all the selected CDs of that artist over all such customers under consideration. In the next section, we derive the time dependent state 
probability vector of the Markov chain via spectral analysis of the underlying transition probability matrix depicted in Figure 1. This in turn enables one to estimate the eight parameters so as to minimize the Euclidian distance between the expected number of CDs sold over 20 weeks calculated from the Markov model and that obtained from the actual POS data. The resulting parameter values are then used to understand the brand characteristics of the five leading Japanese music artists, thereby providing a basis to suggest new effective marketing strategies.

\section{Estimation of Eight Parameter Values via Spectral Analysis of Transition Probability Matrix}

The Markov chain in discrete time for describing the purchasing behavior of a customer between time -2 and time 0 is governed by the one step transition probability matrix $\underline{a}_{I J}^{*}$ given by

$$
\underline{\underline{a}}_{I J}^{*}=\left[\begin{array}{ccccc}
\alpha_{1: I J} & \beta_{1: I J} & 0 & 0 & 0 \\
0 & \alpha_{2: I J} & \beta_{2: I J} & 0 & \gamma_{2: I J} \\
0 & 0 & \alpha_{3: I J} & 0 & \gamma_{3: I J} \\
0 & 0 & 0 & 1 & 0 \\
0 & 0 & 0 & 0 & 1
\end{array}\right]
$$

where $a_{I J: 34}^{*}=0$ since the CD cannot be purchased prior to its release. After time 0 , this transition probability matrix is altered by setting $a_{I J: 34}=\beta_{3: I J}$, i.e.,

$$
\underline{a}_{I J}=\left[\begin{array}{ccccc}
\alpha_{1: I J} & \beta_{1: I J} & 0 & 0 & 0 \\
0 & \alpha_{2: I J} & \beta_{2: I J} & 0 & \gamma_{2: I J} \\
0 & 0 & \alpha_{3: I J} & \beta_{3: I J} & \gamma_{3: I J} \\
0 & 0 & 0 & 1 & 0 \\
0 & 0 & 0 & 0 & 1
\end{array}\right]
$$

Since $\underline{a}_{I J}$ is upper triangular, its eigenvalues are given by $\alpha_{1: I J}, \alpha_{2: I J}$, and $\alpha_{3: I J}$ which are simple, and 1 with multiplicity two. For $M \stackrel{\text { def }}{=}\{1,2,3,4,5\}$, based on the spectral analysis outlined in Appendix, one has

$$
\underline{\underline{a}}_{I J}=\sum_{m \in M} \eta_{I J-m} \underline{\widehat{\underline{J}}}_{I J-m} ; \eta_{I J-m} \stackrel{\text { def }}{=} \begin{cases}\alpha_{m: I J} & \text { if } m=1,2 \text { or } 3 \\ 1 & \text { if } m=4 \text { or } 5\end{cases}
$$

where $\widehat{\underline{J}}_{I J-m}$ are specified in Appendix. Since $\underline{\underline{J}}_{I J-m}$ are idempotent and matrix orthogonal to each other, it follows that

$$
\underline{\underline{a}}_{I J}^{\tau}=\sum_{m \in M} \eta_{I J-m}^{\tau} \underline{\widehat{J}}_{I J-m}(\tau=0,1,2, \ldots),
$$

where $\underline{\underline{a}}_{I J}^{0}=\sum_{m \in M} \widehat{\widehat{J}}_{I J-m}=\underline{\underline{I}}$.

Given $(I, J) \in \mathcal{I} \times \mathcal{J}$, the matrix $\underline{\underline{a}}_{I J}$ can be determined in terms of the eight parameters in Table 4. Furthermore, based on Table 5, the initial state probability vector of a customer in the $(I, J)$ segment at time -2 is given by

$$
\underline{p}_{I J}^{\top}(-2)= \begin{cases}(1,0,0,0,0) & \text { if } J=\text { Ins } \\ (0,1,0,0,0) & \text { if } J=\text { Nor } \\ (0,0,1,0,0) & \text { if } J=\text { Sen or Usen }\end{cases}
$$


which would be applied to $\underline{a}_{I J}^{*}$ in (5.1), yielding $\underline{p}_{I J}^{\top}(0)$ after two transitions. Consequently, the corresponding state probability vector at week $\tau$, denoted by $\underline{p}_{I J}(\tau) \stackrel{\text { def }}{=}\left[p_{I J: 1}(\tau), \ldots, p_{I J: 5}(\tau)\right]^{\top}$, can be computed from (5.4) and (5.5) as

$$
\underline{p}_{I J}^{\top}(\tau)=\underline{p}_{I J}^{\top}(-2) \underline{\underline{a}}_{I J}^{*} \underline{\underline{a}}_{I J}^{\tau}=\sum_{m \in M} \eta_{I J-m}^{\tau} \underline{p}_{I J}^{\top}(0) \underline{\widehat{\widehat{J}}}_{I J-m}(\tau=0,1, \ldots, 20) .
$$

Let $Z_{I J: a}(\tau)$ be the expected number of CDs of artist $a$ purchased by those customers in the $(I, J)$ segment during week $\tau$, and define

$$
Z_{a}(\tau) \stackrel{\text { def }}{=} \sum_{(I, J) \in \mathcal{I} \times \mathcal{J}} Z_{I J: a}(\tau)
$$

Since state 4 corresponding to the decision of purchasing is absorbing as shown in Figure 1, it follows that

$$
Z_{I J: a}(\tau)=N_{P O S} \cdot Q_{I J}(a)\left\{p_{I J: 4}(\tau)-p_{I J: 4}(\tau-1)\right\}, \tau=1, \ldots, 20 .
$$

From (5.6), (5.7) and (5.8), one finds that

$$
\begin{aligned}
& Z_{a}(\tau+1) \\
= & N_{P O S} \sum_{I \in \mathcal{I}}\left[Q_{I, U s e n}(a)\left[r_{I}\left\{1-\left(p_{I}+\xi\right) \zeta\right\}\right]^{\tau}\left(p_{I}+\xi\right) \zeta+Q_{I, S e n}(a)\left\{r_{I}\left(1-p_{I} \zeta\right)\right\}^{\tau} p_{I} \zeta\right. \\
& +Q_{I, N o r m}(a) \frac{p_{I} \zeta r_{I}^{\tau-1}}{1-\zeta}\left\{\left(1-p_{I} \zeta\right)^{\tau}-\left(1-p_{I}\right)^{\tau}\right\}+Q_{I, I n s}(a) \frac{p_{I}^{2} \zeta}{\left(1-r_{I}\right)(1-\zeta) \chi_{I}} \\
& \left.\cdot\left[p_{I}(1-\zeta)\left(1-p_{I}\right)^{\tau-1}+\chi_{I}\left\{r_{I}\left(1-p_{I}\right)\right\}^{\tau-1}-\left(1-r_{I}\right) r_{I}^{\tau-1}\left(1-p_{I} \zeta\right)^{\tau}\right]\right]
\end{aligned}
$$

where

$$
\chi_{I} \stackrel{\text { def }}{=}\left(1-r_{I}\right)-p_{I}\left(1-r_{I} \zeta\right) .
$$

We are now in a position to estimate the values of the eight parameters so as to minimize the Euclidian distance between the expected number of CDs sold over 20 weeks calculated from the Markov model and the actual POS data. More specifically, let $d_{a}(\tau)$ be the average sales of CDs of artist $a$ in week $\tau(\tau=1, \ldots, 20)$ obtained from the POS data, where the average is taken over all the CDs of artist $a$ chosen for the study. We then define

$$
D_{a}(20) \stackrel{\text { def }}{=} \sum_{\tau=1}^{20} d_{a}(\tau)
$$

Of interest is to estimate the values of the eight parameters by minimizing

$$
\varepsilon(a) \stackrel{\text { def }}{=} \sqrt{\frac{\sum_{M=1}^{20}\left\{\sum_{\tau=1}^{M} Z_{a}(\tau)-\sum_{\tau=1}^{M} d_{a}(\tau)\right\}^{2}}{\left\{D_{a}(20)\right\}^{2}}} .
$$

By differentiating $\varepsilon^{2}(a)$ with respect to $x \in\left\{p_{A d d}, p_{F a n}, p_{N e u}, r_{A d d}, r_{F a n}, r_{N e u}, \zeta, \xi\right\}$, it can be readily seen that

$$
\frac{\partial}{\partial x} \varepsilon(a)^{2}=\frac{2}{\left\{D_{a}(20)\right\}^{2}} \sum_{M=1}^{20}\left[\sum_{\tau=1}^{M}\left\{Z_{a}(\tau)-d_{a}(\tau)\right\}\right]\left\{\sum_{\tau=1}^{M} \frac{\partial}{\partial x} Z_{a}(\tau)\right\},
$$


where $\frac{\partial}{\partial x} Z_{a}(\tau)$ for $x \in\left\{p_{\text {Add }}, p_{F a n}, p_{N e u}, r_{A d d}, r_{F a n}, r_{N e u}, \zeta, \xi\right\}$ are given in Appendix. Using MATLAB as a programming language, $\left(p_{\text {Add }}^{*}, p_{F a n}^{*}, p_{N e u}^{*}, r_{A d d}^{*}, r_{F a n}^{*}, r_{N e u}^{*}, \zeta^{*}, \xi^{*}\right)$ can be determined by solving $\frac{\partial}{\partial x} \varepsilon(a)^{2}=0$ for $x \in\left\{p_{A d d}, p_{F a n}, p_{N e u}, r_{A d d}, r_{F a n}, r_{N e u}, \zeta, \xi\right\}$. Summarized in Tables 6 and 7 are the estimated eight parameter values for each of the five artists. Figure 2 demonstrates the excellent fit between the expected number of CDs sold over 20 weeks calculated from the Markov model and the actual POS data, where the logarithmic values are plotted to observe the tail behavior better as suggested by an anonymous referee.

Mr. Children

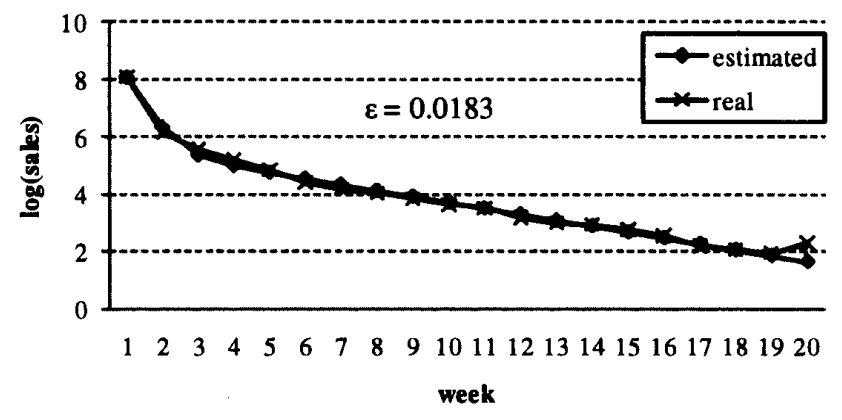

Ken Hirai

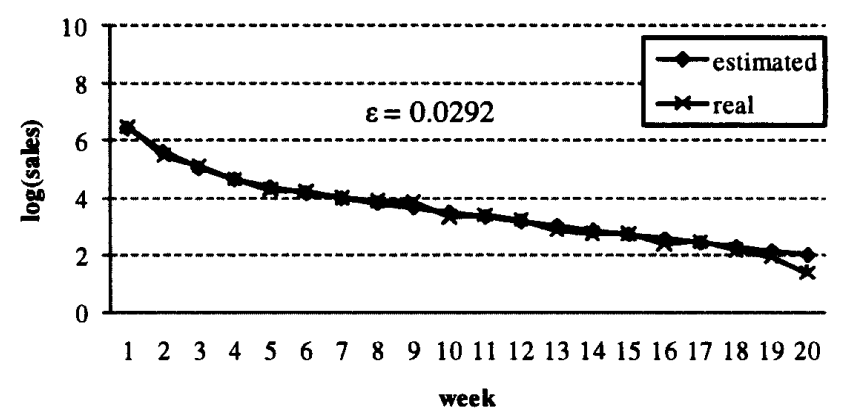

EXILE

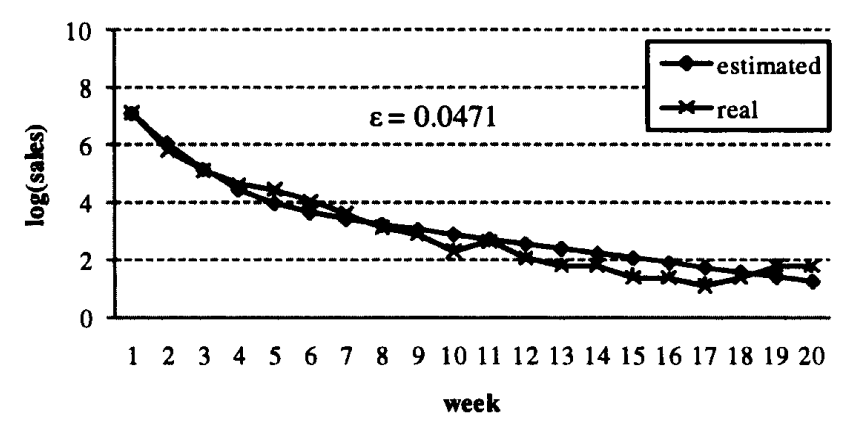

Ketsumeishi

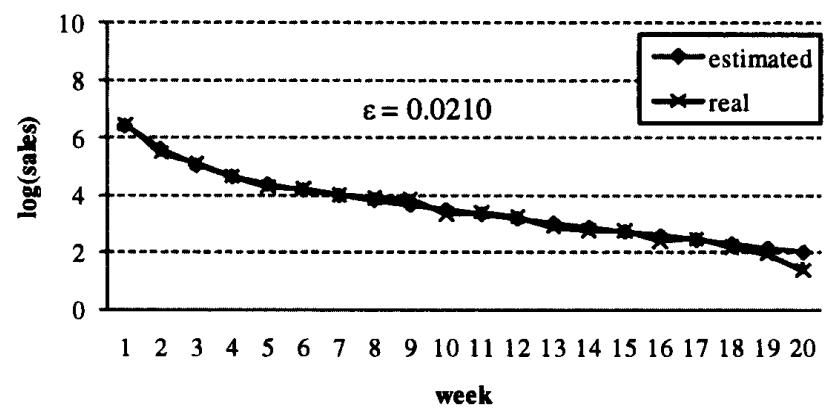

Ayumi Hamasaki

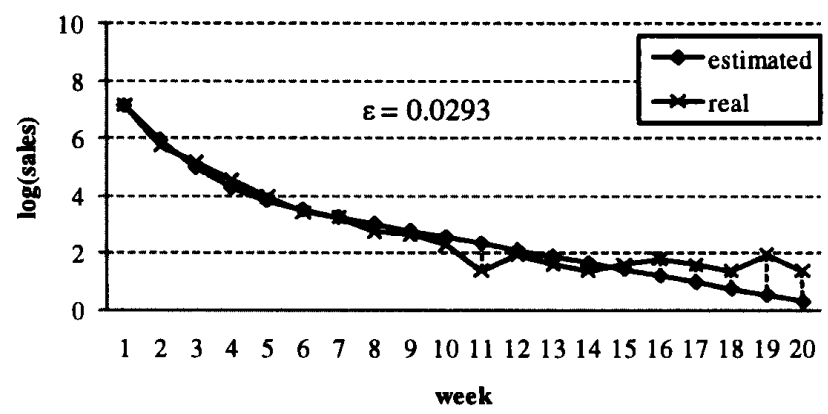

Figure 2: The expected number of CDs sold over 20 weeks based on the Markov model and the actual POS data 
Table 7: Estimated values of eight parameters and resulting transition probabilities based on the POS data for $J \neq U$ sen

\section{Artist Name}

(\# of CDs Sold

per Music Piece)

\begin{tabular}{|c|c|c|}
\hline $\begin{array}{l}\text { Mr.Children } \\
(4780)\end{array}$ & $\begin{array}{r}\text { Parameter } \\
\text { Values }\end{array}$ & $\begin{array}{ccccccccc}p_{A d d}^{*} & p_{F a n}^{*} & p_{N e u}^{*} & r_{\text {Add }}^{*} & r_{F a n}^{*} & r_{N e u}^{*} & \zeta^{*} & \xi^{*} & \varepsilon^{*} \\
0.9999 & 0.9999 & 0.8818 & 0.8963 & 0.8949 & 0.0001 & 0.0932 & 0.0001 & 0.0183\end{array}$ \\
\hline
\end{tabular}

1288 Add 0.00560 .00010 .00010 .81280 .99990 .99990 .09320 .00000 .0940

2261 Fan 0.00980 .00010 .00010 .81150 .99990 .99990 .09320 .00000 .0953 $227384 \mathrm{Neu} 0.98460 .11820 .00000 .00010 .88180 .88180 .08220 .11820 .9177$ 230933 W.A. 1.00000 .11640 .00000 .01260 .88360 .88360 .08240 .11640 .9051

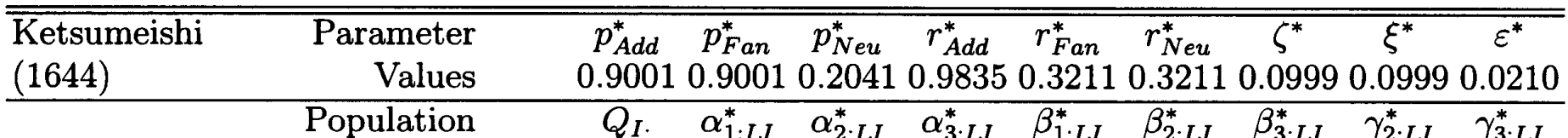

644 Add 0.00280 .09990 .09830 .89510 .90010 .90010 .08990 .00160 .0150

1421 Fan 0.00620 .09990 .03210 .29220 .90010 .90010 .08990 .06780 .6179 228868 Neu 0.99110 .79590 .25560 .31460 .20410 .20410 .02040 .54040 .6651 230933 W.A. 1.00000 .78970 .25380 .31600 .21030 .21030 .02100 .53600 .6630

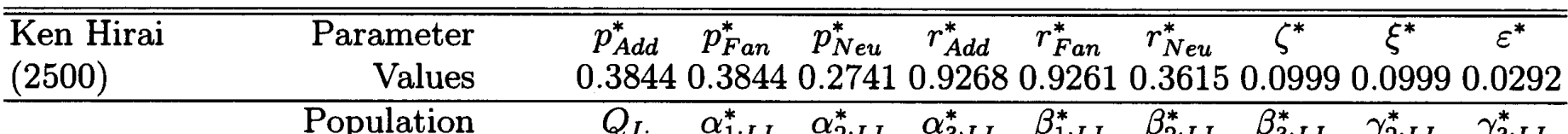

364 Add 0.00160 .61560 .57050 .89120 .38440 .38440 .03840 .04510 .0704

1165 Fan 0.00500 .61560 .57010 .89050 .38440 .38440 .03840 .04550 .0711 229404 Neu 0.99340 .72590 .26240 .35160 .27410 .27410 .02740 .46350 .6210 230933 W.A. $1.0000 \quad 0.72520 .26450 .35520 .27480 .27480 .02750 .46070 .6174$

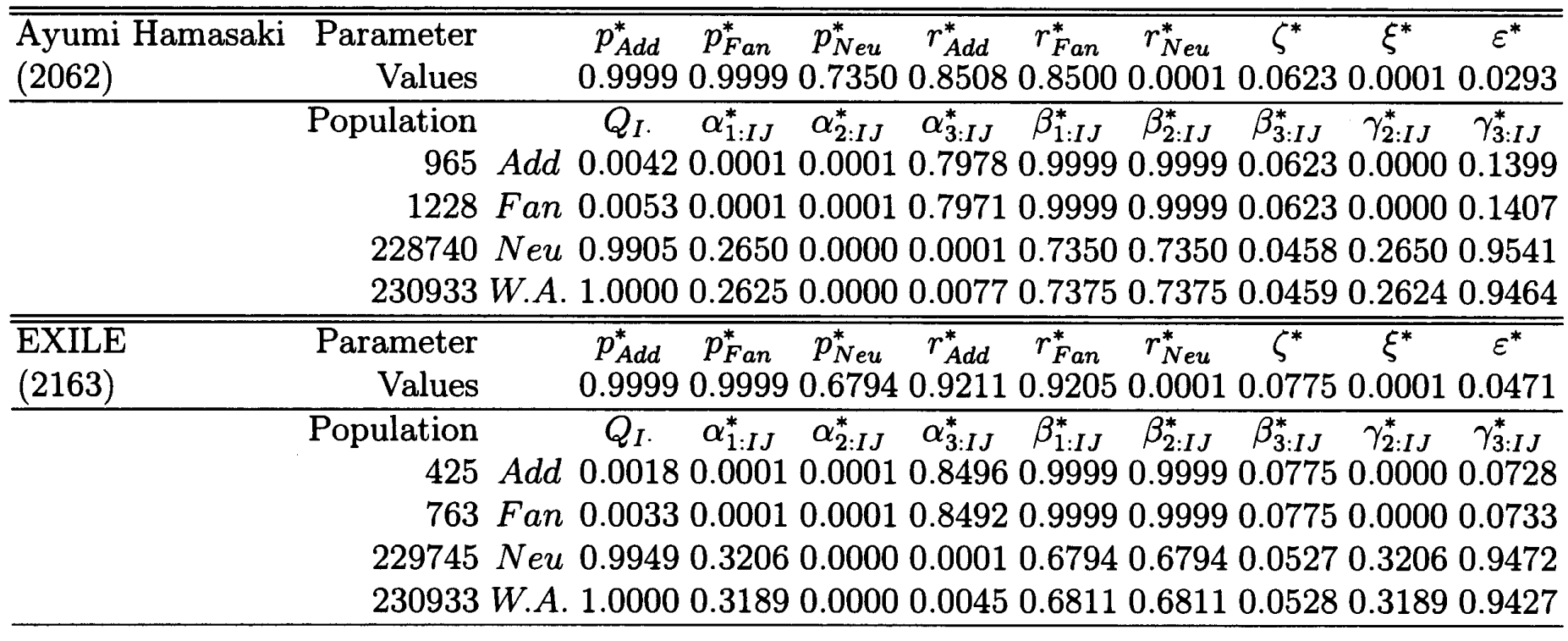




\section{Assessment of Brand Characteristics of the Five Artists}

In this section, we evaluate the brand characteristics of the five Japanese music artists selected in Section 2. Their strengths and weaknesses can be captured based on the eight estimated parameter values obtained in Section 5. For this purpose, it should be noted that the strong presence of a music artist in the CD market may be characterized by the following three factors:

1) the overall brand power in terms of the total number of CDs sold;

2) the rapid sales growth upon release of a CD;

3) the fat tail of the sales records over a long time period, i.e., the CD continues to sell for a long time although the sales speed may not be necessarily high.

In order to establish certain performance indicators for capturing these factors, we first consider a customer whose purchasing behavior can be characterized by the Markov chain in discrete time on $\mathcal{N} \stackrel{\text { def }}{=}\{1,2,3,4,5\}$ governed by $\underline{\underline{a}}$ as introduced in (5.2), where the index $I J$ is dropped for the time being for notational simplicity. We recall that states 4 and 5 are absorbing with the former representing the decision of purchasing and the latter describing that of not purchasing. The state probability vector $\underline{p}^{\top}(\tau)$ at time $\tau$ is available in closed form as given in (5.6) through the spectral analysis of $\underline{\underline{a}}$ discussed in Appendix. The entire market consists of $N$ such customers who behave independently of each other.

Let $S$ be the total number of CDs sold within its product lifecycle. In order to find the probability distribution of $S$, it is necessary to evaluate the absorption probability $\rho_{j: 4}$ that a customer starting at state $j$ eventually reaches state 4 for $j=1,2,3$. Let $G \stackrel{\text { def }}{=}\{1,2,3\}$ and define the submatrix $\underline{a}_{G G} \stackrel{\text { def }}{=}\left[a_{i j}\right]_{i, j \in G}$. One then finds that

$$
\left.\left[\begin{array}{c}
\rho_{1: 4} \\
\rho_{2: 4} \\
\rho_{3: 4}
\end{array}\right]=\underline{\underline{I}}_{G G}-\underline{\underline{a}}_{G G}\right]^{-1}\left[\begin{array}{c}
0 \\
0 \\
\beta_{3}
\end{array}\right] .
$$

The state probability vector at time 0 , denoted by $\underline{p}_{I J}^{\top}(0)$, is common among the customers in the segment $(I, J)$ under consideration. Suppose that the state of such customers at time 0 is state $j$. It can be seen that the total number of CDs sold within its product lifecycle given $j$, denoted by $S_{\mid j}$, has the binomial distribution characterized by the probability generating function

$$
\pi_{\mid j}(u) \stackrel{\text { def }}{=} \mathrm{E}\left[u^{S_{\mid j}}\right]=\left\{1-\rho_{j: 4}+\rho_{j: 4} u\right\}^{N} .
$$

It then follows that

$$
\pi(u) \stackrel{\text { def }}{=} \mathrm{E}\left[u^{S}\right]=\sum_{j=1}^{3} \underline{p}_{I J: j}^{\top}(0) \pi_{\mid j}(u) .
$$

For capturing the overall brand power, of interest is then to evaluate

$$
\psi \stackrel{\text { def }}{=} \frac{\mathrm{E}[S]}{N} ; \quad \kappa \stackrel{\text { def }}{=} \mathrm{P}[S \geqslant K] .
$$

The growth speed of sales of a CD upon its release can be described by the number of CDs purchased by week $\tau$. This random variable, denoted by $S_{H}(\tau)$ where $H$ stands for "Head", clearly has the binomial distribution with the associated probability generating function given by

$$
\pi_{H}(u, \tau) \stackrel{\text { def }}{=} \mathrm{E}\left[u^{S_{H}(\tau)}\right]=\left\{1-p_{4}(\tau)+p_{4}(\tau) u\right\}^{N}
$$


In parallel with (6.4), we define

$$
\psi_{H}(\tau) \stackrel{\text { def }}{=} \frac{\mathrm{E}\left[S_{H}(\tau)\right]}{N} ; \quad \kappa_{H}(\tau) \stackrel{\text { def }}{=} \mathrm{P}\left[S_{H}(\tau) \geqslant K_{H}\right]
$$

As for expressing the strength of having a fat tail of sales, let $\underline{V}^{\top}(\tau) \stackrel{\text { def }}{=}\left[V_{1}(\tau), V_{2}(\tau), V_{3}(\tau)\right]$ be a stochastic vector describing the purchasing behavior of a customer defined by, for $j=1,2,3$,

$$
V_{j}(\tau) \stackrel{\text { def }}{=} \begin{cases}1 & \text { if the customer is in state } j \text { at time } \tau \text { and would eventually } \\ \text { purchase the CD after } \tau & \text { else. }\end{cases}
$$

Let $\underline{u}^{\top} \stackrel{\text { def }}{=}\left[u_{1}, u_{2}, u_{3}\right]$ and define the associated multivariate probability generating function by

$$
\varphi(\underline{u}, \tau) \stackrel{\text { def }}{=} \mathrm{E}\left[\underline{u}^{\underline{V}(\tau)}\right]=\mathrm{E}\left[\prod_{j=1}^{3} u_{j}^{V_{j}(\tau)}\right] .
$$

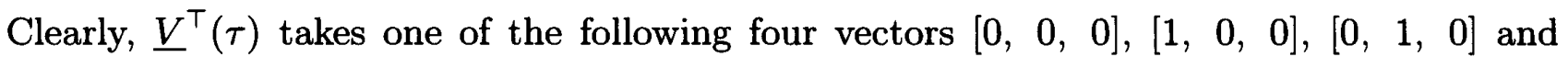
$[0,0,1]$ with probabilities $1-\eta(\tau), p_{1}(\tau) \rho_{1: 4}, p_{2}(\tau) \rho_{2: 4}$ and $p_{3}(\tau) \rho_{3: 4}$ respectively, where

$$
\eta(\tau) \stackrel{\text { def }}{=} p_{1}(\tau) \rho_{1: 4}+p_{2}(\tau) \rho_{2: 4}+p_{3}(\tau) \rho_{3: 4}
$$

It then follows that

$$
\varphi(\underline{u}, \tau)=1-\eta(\tau)+p_{1}(\tau) \rho_{1: 4} u_{1}+p_{2}(\tau) \rho_{2: 4} u_{2}+p_{3}(\tau) \rho_{3: 4} u_{3}
$$

Since we are interested in knowing whether or not a customer eventually reaches state 4 starting from one of the three states in $G=\{1,2,3\}$, we set $u_{1}=u_{2}=u_{3}=u$ so that the resulting probability generating function becomes

$$
\widehat{\varphi}(u, \tau) \stackrel{\text { def }}{=} \varphi(u \underline{1}, \tau)=1-\eta(\tau)+\eta(\tau) u
$$

Let $S_{T}(\tau)$ be the number of CDs purchased after time $\tau$, where $T$ denotes "Tail". It can be readily seen that the probability generating function of $S_{T}(\tau)$ is obtained as

$$
\varphi_{T}(u, \tau) \stackrel{\text { def }}{=} \mathrm{E}\left[u^{S_{T}(\tau)}\right]=\{\widehat{\varphi}(u, \tau)\}^{N}=\{1-\eta(\tau)+\eta(\tau) u\}^{N}
$$

As for (6.4) and (6.6), the key performance indicators for capturing the strength of having a fat tail of CD sales can then be defined by

$$
\psi_{T}(\tau) \stackrel{\text { def }}{=} \frac{\mathrm{E}\left[S_{T}(\tau)\right]}{N} ; \quad \kappa_{T}(\tau) \stackrel{\text { def }}{=} \mathrm{P}\left[S_{T}(\tau) \geqslant K_{T}\right]
$$

Using the key performance indicators in (6.4), (6.6) and (6.13), we now assess the brand characteristics of the five Japanese music artists. It should be noted that, given an artist $a$ and the market segment $(I, J) \in \mathcal{I} \times \mathcal{J}$, one has $N_{I J}(a)$ and the eight estimated parameter values, as well as the initial state of the individual customers in this market segment at time -2 . In order to emphasize the specification of an artist $a$ and the market segment 
$(I, J) \in \mathcal{I} \times \mathcal{J}$, the random variables $S, S_{H}(\tau)$ and $S_{T}(\tau)$ in the above discussion are denoted by $S_{I J: a} S_{H: I J: a}(\tau)$ and $S_{T: I J: a}(\tau)$ respectively. The key performance indicators $\psi_{I J: a}, \kappa_{I J: a}(\tau)$, etc. are written similarly. We now define

$$
S_{I: a} \stackrel{\text { def }}{=} \sum_{J \in \mathcal{J}} S_{I J: a}, S_{H: I: a}(\tau) \stackrel{\text { def }}{=} \sum_{J \in \mathcal{J}} S_{H: I J: a}(\tau), S_{T: I: a}(\tau) \stackrel{\text { def }}{=} \sum_{J \in \mathcal{J}} S_{T: I J: a}(\tau),
$$

and

$$
S_{a} \stackrel{\text { def }}{=} \sum_{I \in \mathcal{I}} S_{I: a}, S_{H: a}(\tau) \stackrel{\text { def }}{=} \sum_{I \in \mathcal{I}} S_{H: I: a}(\tau), S_{T: a}(\tau) \stackrel{\text { def }}{=} \sum_{I \in \mathcal{I}} S_{T: I: a}(\tau)
$$

The corresponding probability generating functions can then be obtained as

$$
\begin{gathered}
\pi_{I: a}(u) \stackrel{\text { def }}{=} \mathrm{E}\left[u^{S_{I: a}}\right]=\prod_{J \in \mathcal{J}} \pi_{I J: a}(u), \\
\pi_{H: I: a}(u, \tau) \stackrel{\text { def }}{=} \mathrm{E}\left[u^{S_{H: I: a}(\tau)}\right]=\prod_{J \in \mathcal{J}} \pi_{H: I J: a}(u, \tau), \\
\pi_{T: I: a}(u, \tau) \stackrel{\text { def }}{=} \mathrm{E}\left[u^{S_{T: I: a}(\tau)}\right]=\prod_{J \in \mathcal{J}} \pi_{T: I J: a}(u, \tau),
\end{gathered}
$$

and

$$
\begin{aligned}
\pi_{a}(u) & \stackrel{\text { def }}{=} \mathrm{E}\left[u^{S_{a}}\right]=\prod_{I \in \mathcal{I}} \pi_{I: a}(u), \\
\pi_{H: a}(u, \tau) & \stackrel{\text { def }}{=} \mathrm{E}\left[u^{S_{H: a}(\tau)}\right]=\prod_{I \in \mathcal{I}} \pi_{H: I: a}(u, \tau), \\
\pi_{T: a}(u, \tau) & \stackrel{\text { def }}{=} \mathrm{E}\left[u^{S_{T: a}(\tau)}\right]=\prod_{I \in \mathcal{I}} \pi_{T: I: a}(u, \tau) .
\end{aligned}
$$

Given an artist $a$, by employing the eight parameter values estimated from the POS data, the key performance indicators in (6.4), (6.6) and (6.13) can be computed for each $I \in \mathcal{I}$ and for the entire market via discrete convolutions based on (6.16) through (6.21). For examining the speed of sales growth upon release, we focus on the first five weeks. In order to investigate the strength of a fat tail of sales records, we consider the period after ten weeks. The values of $K_{I}, K_{H: I}$ and $K_{T: I}$ for describing the tail probability performance measures $\kappa_{I}, \kappa_{H: I}$ and $\kappa_{T: I}$ respectively are set as given in Table 8.

Table 8: $K_{I}, K_{H: I}$ and $K_{T: I}$

\begin{tabular}{cccc}
\hline & $K_{I}$ & $K_{H: I}$ & $K_{T: I}$ \\
\hline \hline Add & 200 & 50 & 50 \\
Fan & 500 & 100 & 100 \\
Neu & 2000 & 1850 & 50 \\
Total & 2700 & 2000 & 200 \\
\hline
\end{tabular}

The final computational results are summarized in Tables 9 through 11 for $I \in \mathcal{I}=$ $\{$ Add, Fan, Neu\} for each artist. By examining these tables, the following observations can be made. 
Table 9: $\mathrm{E}\left[S_{I: a}\right], \psi_{I: a}$ and $\kappa_{I: a}$ based on the POS data

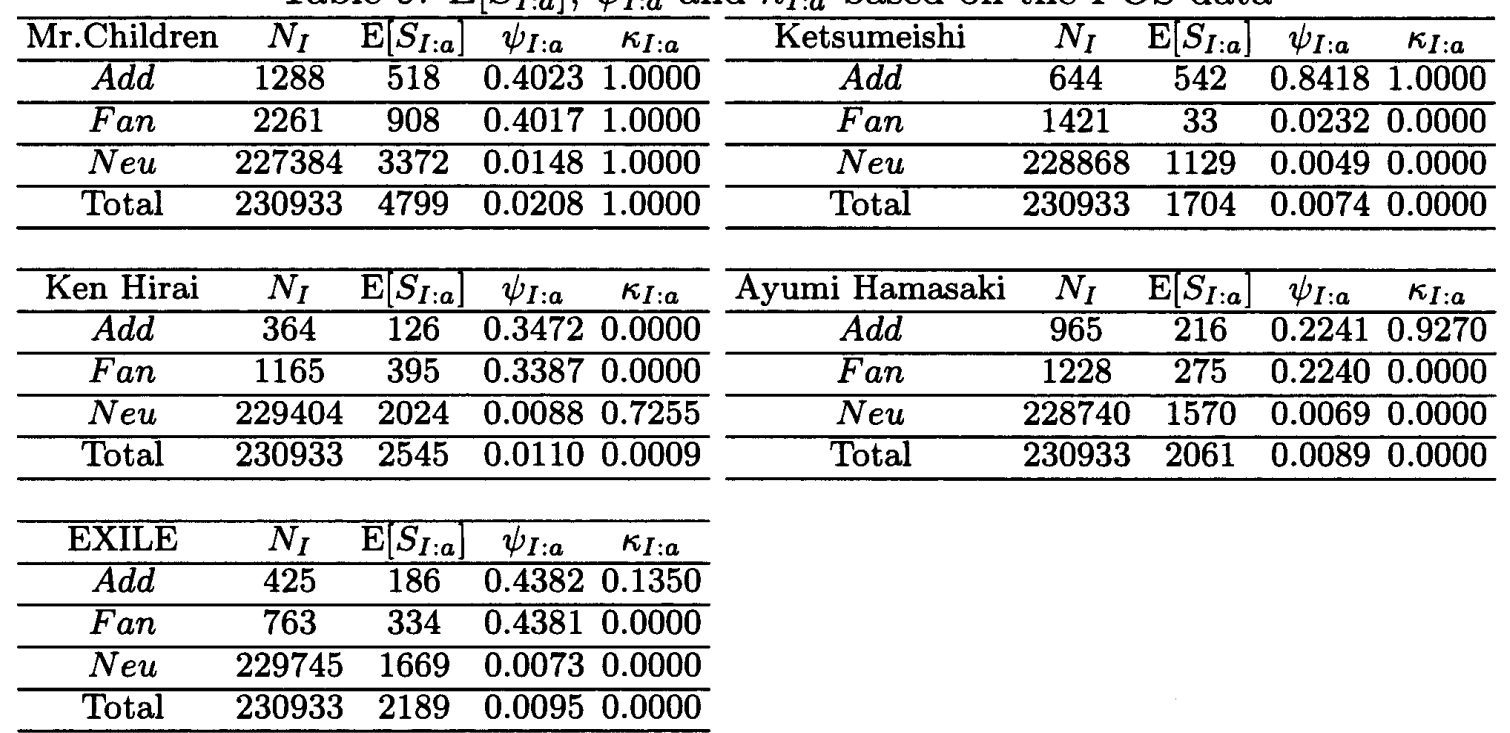

Table 10: $\mathrm{E}\left[S_{H: I: a}(5)\right], \psi_{H: I: a}(5)$ and $\kappa_{H: I: a}(5)$ based on the POS data

\begin{tabular}{|c|c|c|c|c|c|c|c|}
\hline Mr.Children & $N_{I}$ & $\mathrm{E}\left[S_{H: I: a}\right.$ & $\psi_{H: I: a} \quad \kappa_{H: I: a}$ & Ketsumeishi & $\overline{N_{I}}$ & $\mathrm{E}\left[S_{H: I: a}\right]$ & $\psi_{H: I: a} \quad \kappa_{H: I: a}$ \\
\hline$A d d$ & 1288 & 334 & 0.25961 .0000 & Add & 644 & 244 & 0.37961 .0000 \\
\hline Fan & 2261 & 589 & 0.26041 .0000 & Fan & 1421 & 33 & 0.02310 .0000 \\
\hline $\mathrm{Neu}$ & 227384 & 3372 & $0.0148 \quad 1.0000$ & $\overline{N e u}$ & 228868 & 977 & 0.00430 .0000 \\
\hline Total & 230933 & 4295 & 0.01861 .0000 & Total & $\overline{230933}$ & 1254 & 0.00540 .0000 \\
\hline Ken Hirai & $\overline{N_{I}}$ & $\mathrm{E}\left[S_{H: I: a}\right.$ & $\psi_{H: I: a} \quad \kappa_{H: I: a}$ & Ayumi Hamasaki & $N_{I}$ & $\mathrm{E}\left[S_{H: I: a}\right]$ & $\psi_{H: I: a} \quad \kappa_{H: I}$ \\
\hline$A d d$ & 364 & 58 & 0.15860 .9319 & $A d d$ & 965 & 146 & 0.15161 .0000 \\
\hline Fan & 1165 & 177 & 0.15221 .0000 & Fan & 1228 & $18 \overline{7}$ & 0.15191 .0000 \\
\hline $\mathrm{Neu}$ & $\overline{229404}$ & 1806 & 0.00790 .1616 & $\overline{N e u}$ & $\overline{228740}$ & 1568 & 0.00690 .0000 \\
\hline Total & $\overline{230933}$ & 2041 & $0.0088 \quad 0.8335$ & Total & $\overline{230933}$ & 1901 & 0.00820 .0116 \\
\hline
\end{tabular}

\begin{tabular}{cccccc}
\hline EXILE & $N_{I}$ & $\mathrm{E}\left[S_{H: I: a}\right]$ & $\psi_{H: I: a}$ & $\kappa_{H: I: a}$ \\
\hline Add & 425 & 104 & 0.2441 & 1.0000 \\
\hline Fan & 763 & 187 & 0.2447 & 1.0000 \\
\hline Neu & 229745 & 1663 & 0.0072 & 0.0000 \\
\hline Total & 230933 & 1954 & 0.0085 & 0.1520 \\
\hline
\end{tabular}

\section{Mr.Children:}

- In the urban areas represented by the POS data, Mr.Children has the strongest overall brand power among the five music artists with $\mathrm{E}[S]=4799$ and $\kappa=\mathrm{P}[S \geqslant 2700]=$ 1.0000 .

- This strength comes from excelling in the rapid sales growth upon release of a CD with $\mathrm{E}\left[S_{H}(5)\right]=4295$ and $\kappa_{H}(5)=\mathrm{P}\left[S_{H}(5) \geqslant 2000\right]=1.0000$.

- As far as the support of Fan is concerned, one sees that $\psi_{F a n}=\mathrm{E}\left[S_{F a n}\right] / N_{F a n}=0.4017$ and $\kappa_{F a n}=\mathrm{P}\left[S_{F a n} \geqslant 500\right]=1.0000$, i.e., $40 \%$ of $F$ an on the average would purchase a $\mathrm{CD}$ and the total number of CDs sold to Fan would exceed 500 with probability one.

- Such fans are split into three groups: $65 \%$ of them responding soon after the release of a CD $\left(\mathrm{E}\left[S_{H: F a n}\right] / \mathrm{E}\left[S_{F a n}\right]=0.6481\right), 12 \%$ of them contributing to the fat tail strength $\left(\mathrm{E}\left[S_{T: F a n}\right] / \mathrm{E}\left[S_{F a n}\right]=0.1238\right)$, and the remaining $23 \%$ purchasing in between.

- In terms of the total number of CDs sold, the contribution from $\mathrm{Neu}$ is larger than that 
Table 11: $\mathrm{E}\left[S_{T: I: a}(10)\right], \psi_{T: I: a}(10)$ and $\kappa_{T: I: a}(10)$ based on the POS data

\begin{tabular}{ccccc}
\hline Mr.Children & $N_{I}$ & $\mathrm{E}\left[S_{T: I: a}\right]$ & $\psi_{T: I: a}$ & $\kappa_{T: I: a}$ \\
\hline Add & 1288 & 65 & 0.0506 & 0.9903 \\
\hline Fan & 2261 & 112 & 0.0498 & 0.9288 \\
\hline Neu & 227384 & 0 & 0.0000 & 0.0000 \\
\hline Total & 230933 & 178 & 0.0008 & 0.0652 \\
\hline
\end{tabular}

\begin{tabular}{ccccc}
\hline Ketsumeishi & $N_{I}$ & $\mathrm{E}\left[S_{T: I: a}\right]$ & $\psi_{T: I: a}$ & $\kappa_{T: I: a}$ \\
\hline Add & 644 & 163 & 0.2536 & 1.0000 \\
\hline Fan & 1421 & 0 & 0.0000 & 0.0000 \\
\hline Neu & 228868 & 48 & 0.0002 & 0.5250 \\
\hline Total & 230933 & 211 & 0.0009 & 0.8571 \\
\hline
\end{tabular}

\begin{tabular}{ccccc}
\hline Ken Hirai & $N_{I}$ & $\mathrm{E}\left[S_{T: I: a}\right]$ & $\psi_{T: I: a}$ & $\kappa_{T: I: a}$ \\
\hline Add & 364 & 37 & 0.1016 & 0.0375 \\
\hline Fan & 1165 & 118 & 0.1011 & 0.9778 \\
\hline Neu & 229404 & 43 & 0.0002 & 0.2500 \\
\hline Total & 230933 & 198 & 0.0009 & 0.5075 \\
\hline
\end{tabular}

\begin{tabular}{ccccc}
\hline Ayumi Hamasaki & $N_{I}$ & $\mathrm{E}\left[S_{T: I: a}\right]$ & $\psi_{T: I: a}$ & $\kappa_{T: I: a}$ \\
\hline Add & 965 & 23 & 0.0234 & 0.0000 \\
\hline Fan & 1228 & 28 & 0.0232 & 0.0000 \\
\hline Neu & 228740 & 0 & 0.0000 & 0.0000 \\
\hline Total & 230933 & 51 & 0.0002 & 0.0000 \\
\hline
\end{tabular}

\begin{tabular}{ccccc}
\hline EXILE & $N_{I}$ & $\mathrm{E}\left[S_{T: I: a}\right]$ & $\psi_{T: I: a}$ & $\kappa_{T: I: a}$ \\
\hline Add & 425 & 37 & 0.0860 & 0.0327 \\
\hline Fan & 763 & 65 & 0.0854 & 0.0000 \\
\hline Neu & 229745 & 0 & 0.0000 & 0.0000 \\
\hline Total & 230933 & 102 & 0.0004 & 0.0000 \\
\hline
\end{tabular}

of Add or Fan with $\mathrm{E}\left[S_{N e u}\right] / \mathrm{E}[S]=0.7027$. This support is more or less limited to rather quick response to the release of a CD with $\mathrm{E}\left[S_{H: N e u}\right] / \mathrm{E}\left[S_{N e u}\right]=0.9999$. This phenomenon seems to be common also for the other four music artists.

- This means that, in order to sell a CD by a music artist to those who are not necessarily interested in the artist, the efforts ought to be concentrated into the first week or so immediately after releasing the CD. This point is important for cultivating new fans for all of the five selected music artists.

\section{<Suggested Marketing Strategy for Mr.Children>}

Along with EXILE, those supporters of Mr.Children in Fan and Neu seem to have a strong potential in that, on the average, $40 \%$ of $\mathrm{Fan}$ and $1.5 \%$ of $\mathrm{Neu}$ would purchase a CD, in comparison with $2 \%$ and $0.5 \%$ for Ketsumeishi, $34 \%$ and $0.9 \%$ for Ken Hirai, $22 \%$ and $0.7 \%$ for Ayumi Hamasaki, and $44 \%$ and $0.7 \%$ for EXILE. The strong brand power of Mr.Children may be further strengthened by concentrating on conversion of Fan into Add, and Neu into Fan.

\section{Ketsumeishi:}

- The overall brand power of Ketsumeishi is the weakest among the five music artists with $\mathrm{E}[S]=1704$ and $\kappa=\mathrm{P}[S \geqslant 2700]=0.0000$.

- However, it is worth noting that Ketsumeishi has the core of serious supporters who always pay attention to the release of new CDs by the artist with $\psi_{\text {Add }}=\mathrm{E}\left[S_{\text {Add }}\right] / N_{\text {Add }}=$ 0.8418 and $\kappa_{\text {Add }}=\mathrm{P}\left[S_{\text {Add }} \geqslant 200\right]=1.0000$.

- In terms of the expected total sales after week 10 , Ketsumeishi is top among the five artists with $\mathrm{E}\left[S_{T}\right]=211$, followed by Ken Hirai $\left(\mathrm{E}\left[S_{T}\right]=198\right)$, Mr.Children $\left(\mathrm{E}\left[S_{T}\right]=\right.$ 178), EXILE $\left(\mathrm{E}\left[S_{T}\right]=102\right)$ and Ayumi Hamasaki $\left(\mathrm{E}\left[S_{T}\right]=51\right)$.

- This superiority is widened if we focus on $A d d$, where Ketsumeishi has $\psi_{T: A d d}(10)=$ 0.2536 in comparison with Ken Hirai $\left(\psi_{T: A d d}(10)=0.1016\right)$, Mr. Children $\left(\psi_{T: A d d}(10)=\right.$ $0.0506)$, EXILE $\left(\psi_{T: A d d}(10)=0.0860\right)$ and Ayumi Hamasaki $\left(\psi_{T: A d d}(10)=0.0234\right)$.

- The strength of Ketsumeishi supported by Add can also be observed in the rapid growth of the sales during the first five weeks, with Ketsumeishi having $\psi_{H: A d d}(5)=0.3796$, 
whereas Ken Hirai $\left(\psi_{H: A d d}(5)=0.1586\right)$, Mr.Children $\left(\psi_{H: A d d}(5)=0.2596\right)$, EXILE $\left(\psi_{H: A d d}(5)=0.2441\right)$ and Ayumi Hamasaki $\left(\psi_{H: A d d}(5)=0.1516\right)$.

$<$ Suggested Marketing Strategy for Ketsumeishi>

Currently, Ketsumeishi is supported by the core of serious supporters in Add. While this strength may be appreciated, the smallest total sales among the five music artists would indicate that the overall brand power of Ketsumeishi has not been well established in the POP CD market. Accordingly, the efforts would be needed for enhancing the visibility of Ketsumeishi in the market and promoting the sales among $\mathrm{Fan}$ and $\mathrm{Neu}$.

\section{Ken Hirai:}

- Ken Hirai has a fairly strong presence in the CD market with $\mathrm{E}[S]=2545$ and $\kappa=$ $\mathrm{P}[S \geqslant 2700]=0.0009$, only next to Mr.Children.

- This hidden strength relies upon the support from $N e u$ with $\mathrm{E}\left[S_{N e u}\right]=2024$ ranked the second after Mr.Children.

- Such fans are split into three groups: $89 \%$ of them responding soon after the release of a CD $\left(\mathrm{E}\left[S_{H: F a n}\right] / \mathrm{E}\left[S_{F a n}\right]=0.8920\right), 2 \%$ of them contributing to the fat tail strength $\left(\mathrm{E}\left[S_{T: F a n}\right] / \mathrm{E}\left[S_{F a n}\right]=0.0213\right)$, and the remaining $9 \%$ purchasing in between.

\section{$<$ Suggested Marketing Strategy for Ken Hirai>}

The strength of $\mathrm{Neu}$ may suggest that Ken Hirai has not developed the core of serious supporters and his music CDs are bought not because they are composed by Ken Hirai but because their musical contexts are appreciated. For enforcing the presence of Ken Hirai in the CD market, it would be necessary to develop a core of serious supporters who would be attracted to Ken Hirai as a musician, rather than to the musical contexts of his CDs.

\section{Ayumi Hamasaki:}

- The total number of fans in Add or Fan is 2193, the second among the five artists only next to Mr.Children with 3549. However, not many of them did not buy the CDs under consideration, as shown by $\left(\psi_{A d d}, \psi_{F a n}\right)=(0.2241,0.2240)$ in comparison with Mr.Children $(0.4023,0.4017)$, Ketsumeishi $(0.8418,0.0232)$, Ken Hirai $(0.3472,0.3387)$, and EXILE $(0.4382,0.4381)$.

- She is also the weakest among the five artists in terms of the sales in the tail with $\mathrm{E}\left[S_{T}(10)\right]=51$, whereas Mr.Children has this value of 178 , Ketsumeishi 211, Ken Hirai 198, and EXILE 102.

- This suggests that her popularity in the POP CD market in Japan has been declining.

\section{<Suggested Marketing Strategy for Ayumi Hamasaki>}

The most effective marketing strategy for Ayumi Hamasaki would be to revive the core of fans in Add or Fan. It would be also important to make efforts for converting customers in $\mathrm{Neu}$ to $\mathrm{Fan}$ by exercising the special promotional campaign upon releasing a CD, combined with the occasional promotions after 10 weeks since the release so as to increase the tail sales.

\section{EXILE:}

- The strong support from $A d d$ and $F$ an of EXILE can be found in that $\psi_{\text {Add }}=\mathrm{E}\left[S_{\text {Add }}\right] / N_{\text {Add }}=$ 0.4382 and $\psi_{F a n}=\mathrm{E}\left[S_{F a n}\right] / N_{F a n}=0.4381$ respectively, comparable with Mr.Children having the value of 0.4023 and 0.4017 respectively. 
- For the support of Fan, one sees that $\psi_{F a n}=\mathrm{E}\left[S_{F a n}\right] / N_{F a n}=0.4381$ and $\kappa_{F a n}=$ $\mathrm{P}\left[S_{F a n} \geqslant 500\right]=0.0000$, i.e. $44 \%$ of $F a n$ on the average would purchase a CD just like Mr.Children. However, the total number of CDs sold to Fan would exceed 500 with probability 0.0000 , while this probability for Mr.Children is one.

\section{$<$ Suggested Marketing Strategy for EXILE $>$}

The strength of EXILE comes from the support provided by Add and Fan. While their loyalty is quite strong, the volume of them is not sufficient. Accordingly, the most effective marketing strategy is to enhance the visibility of EXILE in Neu so as to creating new fans in Fan and $A d d$.

\section{Concluding Remarks}

In this paper, as in [23], the customer segmentation in the POP CD market is considered, where the customers are classified into twelve segments along two axes: "Artist Loyalty" consisting of three different levels (Addict, Fan, and Neutral), and "Market Sensitivity" with four different levels (Ultra Sensitive, Sensitive, Normal, and Insensitive). The artist loyalty of a customer to a music artist is measured by the number of CDs of the artist purchased by the customer, while the market sensitivity of the customer concerning the POP CD market is defined by considering how soon a CD is purchased by the customer since the release of the CD.

Given a music artist and his/her CD, the purchasing behavior of individual customers for that $\mathrm{CD}$ is formulated as a Markov chain in discrete time defined on the following five states: Unknown, Known, Interested, Purchased, and Not Purchased. Because a music CD is not likely to be purchased repeatedly, the two states, Purchased and Not Purchased, are absorbing. The transition structure of the customers across the twelve segments is common. However, the market segmentation is reflected by altering transition probabilities in terms of eight different parameters. The entire market for the artist is then expressed as an independent sum of all such customers.

The spectral analysis of the transition probability matrix of the Markov chain enables one to obtain the state probability vector in a closed form, which in turn provides the expected number of sales by week $\tau$ since the release and other related measures in a closed form. Using MATLAB, the eight parameters are then estimated so as to minimize the Euclidian distance between the expected number of CDs sold over 20 weeks calculated from the Markov model and the actual POS data obtained from ten CD shops in urban areas in Japan. The resulting parameter values are then used to understand the brand characteristics of the five leading Japanese POP artists, thereby suggesting new effective marketing strategies for them.

It should be noted that, while the paper is written by focusing on the Japanese POP CD market, the proposed approach can be applied to any market in which products are likely to be purchased only once, provided that the data set necessary for estimating the underlying parameter values could be accessible.

Acknowledgement. The authors wish to thank two anonymous referees for providing many valuable suggestions, which contributed to improve the earlier version of the paper substantially. This research is supported by MEXT Grand-in-Aid for Scientific Research (C) 22500082 . 


\section{A. Spectral Analysis of $\underline{\underline{a}}_{I J}$}

In this appendix, the spectral analysis of matrix $\underline{\underline{a}}_{I J}$ of (5.2) in Section 5 is conducted. Since $\underline{\underline{a}}_{I J}$ is upper triangular, its eigenvalues are given by $\alpha_{1: I J}, \alpha_{2: I J}$, and $\alpha_{3: I J}$ which are simple, and 1 with multiplicity two. The right eigenvectors and left eigenvectors are obtained as

$$
\begin{aligned}
& \underline{x}_{I J-1}=\left[\begin{array}{ll}
1,0,0,0,0
\end{array}\right]^{\top}, \\
& \underline{x}_{I J-2}=\left[\beta_{1: I J}, \alpha_{2: I J}-\alpha_{1: I J}, 0,0,0\right]^{\top} \text {, } \\
& \underline{x}_{I J-3}=\left[\beta_{1: I J} \beta_{2: I J},-\left(\alpha_{1: I J}-\alpha_{3: I J}\right) \beta_{2: I J},\left(\alpha_{1: I J}-\alpha_{3: I J}\right)\left(\alpha_{2: I J}-\alpha_{3: I J}\right), 0,0\right]^{\top} \text {, } \\
& \underline{x}_{I J-4}=\left[\beta_{2: I J} \beta_{3: I J}, \beta_{2: I J} \beta_{3: I J},\left(1-\alpha_{2: I J}\right) \beta_{3: I J},\left(1-\alpha_{2: I J}\right)\left(1-\alpha_{3: I J}\right), 0\right]^{\top} \text {, } \\
& \underline{x}_{I J-5}=\left[\beta_{2: I J} \gamma_{3: I J}+\left(1-\alpha_{3: I J}\right) \gamma_{2: I J}, \beta_{2: I J} \gamma_{3: I J}+\left(1-\alpha_{3: I J}\right) \gamma_{2: I J},\left(1-\alpha_{2: I J}\right) \gamma_{3: I J}\right. \text {, } \\
& \left.0,\left(1-\alpha_{2: I J}\right)\left(1-\alpha_{3: I J}\right)\right]^{\top} \text {, } \\
& \underline{y}_{I J-1}=\left[\left(\alpha_{1: I J}-\alpha_{2: I J}\right)\left(\alpha_{1: I J}-\alpha_{3: I J}\right),-\left(\alpha_{3: I J}-\alpha_{1: I J}\right) \beta_{1: I J}, \beta_{1: I J} \beta_{2: I J},-\beta_{2: I J} \beta_{3: I J},\right. \\
& \left.-\Delta_{1: I J}\right]^{\top} \text {, } \\
& \underline{y}_{I J-2}=\left[0,\left(\alpha_{3: I J}-\alpha_{2: I J}\right)\left(1-\alpha_{2: I J}\right),-\left(1-\alpha_{2: I J}\right) \beta_{2: I J}, \beta_{2: I J} \beta_{3: I J}, \Delta_{2: I J}\right]^{\top} \text {, } \\
& \underline{y}_{I J-3}=\left[0,0,1-\alpha_{3: I J},-\beta_{3: I J},-\gamma_{3: I J}\right]^{\top} \text {, } \\
& \underline{y}_{I J-4}=[0,0,0,1,0]^{\top} \text {, } \\
& \underline{y}_{I J-5}=\left[\begin{array}{llll}
0,0,0,0,1
\end{array}\right]^{\top},
\end{aligned}
$$

where $\Delta_{i: I J} \stackrel{\text { def }}{=} \beta_{2: I J} \gamma_{3: I J}-\left(\alpha_{3: I J}-\alpha_{i: I J}\right) \gamma_{2: I J}(i=1,2)$. We define

$$
\begin{aligned}
& \underline{\widehat{x}}_{I J-m} \stackrel{\text { def }}{=} k_{I J-m} \underline{x}_{I J-m}, \underline{\widehat{y}}_{I J-m} \stackrel{\text { def }}{=} k_{I J-m} \underline{y}_{I J-m}, m \in M \stackrel{\text { def }}{=}\{1,2,3,4,5\}, \\
& k_{I J-1} \stackrel{\text { def }}{=} \sqrt{\frac{1}{\left(\alpha_{2: I J}-\alpha_{1: I J}\right)\left(\alpha_{3: I J}-\alpha_{1: I J}\right)}} \\
& k_{I J-2} \stackrel{\text { def }}{=} \sqrt{\frac{1}{\left(\alpha_{2: I J}-\alpha_{1: I J}\right)\left(\alpha_{3: I J}-\alpha_{2: I J}\right)\left(1-\alpha_{2: I J}\right)}}, \\
& k_{I J-3} \stackrel{\text { def }}{=} \sqrt{\frac{1}{\left(\alpha_{1: I J}-\alpha_{3: I J}\right)\left(\alpha_{2: I J}-\alpha_{3: I J}\right)\left(1-\alpha_{3: I J}\right)}}, \\
& k_{I J-4}=k_{I J-5} \stackrel{\text { def }}{=} \sqrt{\frac{1}{\left(1-\alpha_{2: I J}\right)\left(1-\alpha_{3: I J}\right)}} \text {. }
\end{aligned}
$$

One then has

$$
\widehat{\widehat{\underline{y}}}_{I J-m_{1}}^{\top} \widehat{\underline{x}}_{I J-m_{2}}=\delta_{\left\{m_{1}=m_{2}\right\}}, \quad m_{1}, m_{2} \in M .
$$

We also define $\underline{\underline{J}}_{I J-m} \stackrel{\text { def }}{=} \underline{\widehat{x}}_{I J-m} \underline{\widehat{y}}_{I J-m}^{\top}$. It then follows that

$$
\underline{\underline{a}}_{I J}=\sum_{m \in M} \eta_{I J-m} \widehat{\widehat{J}}_{I J-m} ; \eta_{I J-m} \stackrel{\text { def }}{=} \begin{cases}\alpha_{m: I J} & \text { if } m=1,2 \text { or } 3, \\ 1 & \text { if } m=4 \text { or } 5 .\end{cases}
$$

Since $\underline{\underline{\widehat{J}}}_{I J-m_{1}} \widehat{\widehat{J}}_{I J-m_{2}}=\underline{\underline{0}}$ for $m_{1}$ and $m_{2}\left(m_{1} \neq m_{2}, m_{1}, m_{2} \in M\right)$ from (A.1), $\underline{\underline{a}}_{I J}^{\tau}$ is expressed as

$$
\underline{\underline{a}}_{I J}^{\tau}=\sum_{m \in M} \eta_{I J-m}^{\tau} \widehat{\underline{\underline{J}}}_{I J-m}(\tau=0,1, \ldots)
$$


where $\underline{\underline{a}}_{I J}^{0}=\sum_{m \in M} \widehat{\widehat{J}}_{I J-m}=\underline{\underline{I}}$.

B. Derivation of $\frac{\partial}{\partial x} Z_{a}(\tau)$ for $x \in\left\{p_{A d d}, p_{F a n}, p_{N e u}, r_{A d d}, r_{F a n}, r_{N e u}, \zeta, \xi\right\}$

In this section, $\frac{\partial}{\partial x} Z_{a}(\tau)$ for $x \in\left\{p_{A d d}, p_{F a n}, p_{N e u}, r_{A d d}, r_{F a n}, r_{N e u}, \zeta, \xi\right\}$ in (5.13) is provided. By differentiating $Z_{a}(\tau)$ with respect to $x \in\left\{p_{A d d}, p_{F a n}, p_{N e u}, r_{A d d}, r_{F a n}, r_{N e u}, \zeta, \xi\right\}$, it can be seen that

$$
\begin{aligned}
& \frac{\partial}{\partial p_{I}} Z_{a}(\tau)=N_{P O S} \sum_{I \in \mathcal{I}}\left[r_{I}^{\tau-1} \zeta\left[Q_{I, U s e n}(a)\left\{1-\left(p_{I}+\xi\right) \zeta\right\}^{\tau-2}\right]\right. \\
& +Q_{I, S e n}(a)\left(1-p_{I}\right)^{\tau-2}\left(1-\tau p_{I} \zeta\right) \\
& +\frac{\zeta}{1-\zeta}\left[Q_{I, N o r m}(a) r_{I}^{\tau-2}\left\{\left(1-p_{I} \zeta\right)^{\tau-2}\left(1-\tau p_{I} \zeta\right)-\left(1-p_{I}\right)^{\tau-2}\left(1-\tau p_{I}\right)\right\}\right] \\
& +Q_{I, I n s}(a) \cdot \frac{p_{I}}{\left(1-r_{I}\right) \chi_{I}}\left[\frac { 2 \chi _ { I } + p _ { I } ( 1 - r _ { I } \zeta ) } { \chi _ { I } } \left[\left(1-p_{I}\right)^{\tau-2}\left\{p_{I}(1-\zeta)+\chi_{I} r_{I}^{\tau-2}\right\}\right.\right. \\
& \left.-\left(1-r_{I}\right)^{\tau-2}\left(1-p_{I} \zeta\right)^{\tau-1}\right]+p_{I}\left[\left(1-p_{I}\right)^{\tau-2}\left\{(1-\zeta)-r_{I}^{\tau-2}\left(1-r_{I} \zeta\right)\right\}\right. \\
& \left.\left.\left.\left.-(\tau-2)\left(1-p_{I}\right)^{\tau-3}\left\{(1-\zeta) p_{I}\left(1-p_{I}\right)-r_{I}^{\tau-2} \chi_{I}\right\}\right]\right]\right]\right] \text {, } \\
& \frac{\partial}{\partial r_{I}} Z_{a}(\tau)=N_{P O S} \sum_{I \in \mathcal{I}}\left[( \tau - 1 ) r _ { I } ^ { \tau - 2 } \zeta \left[Q_{I, U s e n}(a)\left\{1-\left(p_{I}+\xi\right) \zeta\right\}^{\tau-1}\left(p_{I}+\xi\right)\right.\right. \\
& \left.+Q_{I, S e n}(a)\left(1-p_{I} \zeta\right)^{\tau-1} p_{I}\right]+\frac{p_{I} \zeta}{1-\zeta}\left[Q _ { I , N o r m } ( a ) ( \tau - 2 ) \left\{\left(1-p_{I} \zeta\right)^{\tau-1}\right.\right. \\
& \left.-\left(1-p_{I}\right)^{\tau-1}\right\} r_{I}^{\tau-3}+Q_{I, I n s}(a) \cdot \frac{p_{I}}{\chi_{I}\left(1-r_{I}\right)}\left[\frac{\left(1-p_{I} \zeta\right)\left(1-r_{I}\right)+\chi_{I}}{\chi_{I}\left(1-r_{I}\right)}\right. \\
& \cdot\left[\left(1-p_{I}\right)^{\tau-2}\left\{p_{I}(1-\zeta)+\chi_{I} r_{I}^{\tau-2}\right\}-\left(1-p_{I} \zeta\right)^{\tau-1}\left(1-r_{I}\right) r_{I}^{\tau-2}\right] \\
& +\left(1-p_{I}\right)^{\tau-2} r_{I}^{\tau-3}\left\{(\tau-2) \chi_{I}-\left(1-p_{I} \zeta\right) r_{I}\right\} \\
& \left.\left.\left.-\left(1-p_{I} \zeta\right)^{\tau-1} r_{I}^{\tau-3}\left\{(\tau-2)\left(1-r_{I}\right)-r_{I}\right\}\right]\right]\right] \text {, } \\
& \frac{\partial}{\partial \zeta} Z_{a}(\tau)=N_{P O S} \sum_{I \in \mathcal{I}}\left[r _ { I } ^ { \tau - 1 } \left[Q_{I, U s e n}(a)\left(p_{I}+\xi\right)\left\{1-\left(p_{I}+\xi\right) \zeta\right\}^{\tau-2}\left\{1-\tau\left(p_{I}+\xi\right) \zeta\right\}\right.\right. \\
& \left.+Q_{I, S e n}(a) p_{I}\left(1-p_{I} \zeta\right)^{\tau-2}\left(1-\tau p_{I} \zeta\right)\right]+\frac{p_{I}}{1-\zeta}\left[Q _ { I , N o r m } ( a ) r _ { I } ^ { \tau - 2 } \left[\frac{1}{1-\zeta}\left\{\left(1-p_{I} \zeta\right)^{\tau-1}\right\}\right.\right. \\
& \left.-(\tau-1)\left(1-p_{I} \zeta\right)^{\tau-2} \zeta\right]+Q_{I, I n s}(a) \cdot \frac{p_{I}}{\chi_{I}\left(1-r_{I}\right)}\left[\frac{\chi_{I}-r_{I} p_{I} \zeta(1-\zeta)}{\chi_{I}(1-\zeta)}\right. \\
& \cdot\left[\left(1-p_{I}\right)^{\tau-2}\left\{p_{I}(1-\zeta)+\chi_{I} r_{I}^{\tau-2}\right\}-r_{I}\left(1-r_{I}\right)\left(1-p_{I} \zeta\right)^{\tau-1}\right] \\
& \left.\left.\left.-\zeta\left\{p_{I}\left(1-p_{I}\right)^{\tau-2}\left(1-r_{I}^{\tau-1}\right)-(\tau-1) r_{I}\left(1-r_{I}\right) p_{I}\left(1-p_{I} \zeta\right)^{\tau-2}\right\}\right]\right]\right]
\end{aligned}
$$

and

$$
\frac{\partial}{\partial \xi} Z_{a}(\tau)=N_{P O S} \sum_{I \in \mathcal{I}} Q_{I, U s e n}(a) r_{I}^{\tau-1} \zeta\left\{1-\left(p_{I}+\xi\right) \zeta\right\}^{\tau-2}\left\{1-\tau\left(p_{I}+\xi\right) \zeta\right\}
$$




\section{References}

[1] T.W. Anderson and L.A. Goodman: Statistical inference about Markov chains. Annals of Mathematical Statistics, 28 (1957), 89-110.

[2] F.M. Bass: A new product growth model for consumer durables. Management Science, 15 (1969), 215-227.

[3] W.K. Ching, E.S. Fung and M.K. Ng: A multivariate markov chain model for categorical data sequences and its applications in demand predictions. IMA Journal of Management Mathematics, 13 (2002), 187-199.

[4] J.P. Danaher: A Markov-chain model for multivariate magazine-exposure distributions. Journal of Business \& Economic Statistics, 10-4 (1992), 401-407.

[5] A.S.C. Ehrenberg: An appraisal of Markov brand-switching models. Journal of Marketing Research, 2-4 (1965), 347-362.

[6] S.H. Ha, S.M. Bae and S.C. Park: Customer's time-variant purchase behavior and corresponding marketing strategies: an online retailer's case. Computers $\mathcal{G}$ Industrial Engineering, 43 (2002), 801-820.

[7] F. Harary and B. Lipstein: The dynamics of brand loyalty: A Markovian approach. Operations Research, 10-1 (1962), 19-40.

[8] P.H. Hartung and J.L. Fisher: Brand switching and mathematical programming in market expansion. Management Science, 11-10 (1965), 231-243.

[9] D. Horsky: A diffusion model incorporating product benefits, price income and information. Marketing Science, 9-4 (1990), 342-365.

[10] D. Horsky and L.S. Simon: Advertising and the diffusion of new products. Marketing Science, 2-4 (1983), 1-17.

[11] K. Jedidi, H.S. Jagpal and W.S. Desarbo: Finite-mixture structural equation models for response-based segmentation and unobserved heterogeneity. Marketing Science, 16-1 (1997), 39-59.

[12] O. Kucukemiroglu: Market segmentation by using consumer lifestyle dimensions and ethnocentrism: An emprical study. European Journal of Marketing, 33-5 (1999), 470487.

[13] W.F. Massy and D.G. Morrison: Comments on Ehrenberg's appraisal of brandswitching models. Journal of Marketing Research, 5 (1968), 225-229.

[14] A.L. Montgomery, S. Li, K. Srinivasan and J.C. Liechty: Modeling online browsing and path analysis using clickstream data. Marketing Science, 23-4 (2004), 579-595.

[15] K.R. Moorthy and I.P.L. Png: Market segmentation, cannibalization, and the timing of product introductions. Management Science, 38-3 (1992), 345-359.

[16] G.P. Moschis, E. Lee and A. Mathur: Targeting the mature market: Opportunities and challenges. Journal of Consumer Marketing, 14-4 (1997), 282-293.

[17] O. Netzer, J.M. Latten and V. Srinivasan: A hidden Markov model of customer relationship dynamics. Marketing Science, 27-2 (2008), 185-204.

[18] J.P. Peter and J.C. Olson: Consumer Behavior and Marketing Strategy (McGraw-Hill Education, 1999).

[19] C.S. Poulsen: Mixed Markov and latent Markov modeling applied to brand choice behaviour. International Journal of Research in Marketing, 7 (1990), 5-19.

[20] W.F. Raaij and T.M.M. Verhallen: Domain-specific Market Segmentation. European Journal of Marketing, 28-10 (1994), 49-66. 
[21] R.T. Rust, K.N. Lemon and V.A. Zeithaml: Return on marketing: Using customer equity to focus marketing strategy. Journal of Marketing, 68 (2004), 109-127.

[22] U. Sumita, T. Ise and K. Yonezawa: Stochastic analysis of number of corporations in a market derived from strategic policies of individual corporations for market Entry and retreat. Journal of Operations Research Society of Japan, 49-1 (2006), 1-18.

[23] U. Sumita, K. Saito, K. Takahashi, Y. Koike and T. Sugaya: Structural analysis of brand power of music artists in the Japanese CD market (written in Japanese). Journal of Operations Research Society of Japan, 52-2 (2007), 69-78.

[24] M. Wedel and W.A. Kamakura: Market Segmentation: Conceptual and Methodological Foundations (Kluwer Academic Publishers, 1999).

\section{Ushio Sumita}

Graduate school of Systems and Information Engineering,

University of Tsukuba. 1-1-1 Tennoudai, Tsukuba, Ibaraki 305-8573, Japan

E-mail: sumita@sk.tsukuba.ac.jp 